\title{
Alternâncias nos processos e políticas de formação de professores no Brasil
}

William Xavier de Almeida

Adriana Richit

\section{Resumo}

O artigo propõe algumas reflexões sobre as perspectivas de formação de professores manifestadas no processo de consolidação da educação no Brasil, sobretudo a Educação Básica pública. Para tanto, examinamos o percurso histórico da educação no país apresentado em Saviani (2009), Vieira e Gomide (2008) e Tanuri (2000) e a partir destes trabalhos buscamos discutir as principais perspectivas de formação docente evidenciadas nos distintos momentos em que sucederam-se alternâncias político-econômicas no país. Nossa análise mostra que ao longo do processo de consolidação da educação no Brasil quatro perspectivas principais de formação docente predominaram: formação centrada no conteúdo a ensinar, em que o aspirante a professor aprendia o ofício mediante a observação de um professor experiente; formação centrada nos métodos e técnicas de ensino, a qual era ofertada principalmente nas Escolas Normais e com ênfase no conteúdo a ser ensinado em sala de aula; formação centrada na aprendizagem dos conteúdos a ensinar e na didática, na qual havia preocupação com aspectos do conteúdo curricular a ser ensinado e sobre como ensiná-lo; e formação com uma dimensão intelectual, perspectiva esta que favoreceu a criação dos cursos de licenciatura e pedagogia e elevou a formação de professores ao nível superior, uma vez que incorporava à formação docente a pesquisa e a produção de conhecimento.

Palavras-chave: Formação de professores. Profissionalidade docente. Conhecimento profissional docente. 


\section{Alternations in teachers' education policies and processes in Brazil}

William Xavier de Almeida

Adriana Richit

\section{Abstract}

The paper proposes some reflections about the perspectives of teachers' education manifested in the consolidation process of education in Brazil, especially, the public and basic education. For this, we examine the historic course of education in the country introduced by Saviani (2009), Vieira and Gomide (2008) and Tanuri (2000) and beginning from this works we seek to discuss the main perspectives of teachers' education evidenced in the distinct moments in which economic and politic alternations happened in the country. Our analysis shows that through the consolidation process of education in Brazil four main perspectives of teachers' education prevail: education focused in the content to teach, in which the teacher learned the profession through the observation of an experienced teacher; education focused on methods and techniques of teaching, which was offered mainly in the Normal Schools, with emphasis in the content to be taught in the classroom; education focused in the contents to be taught and didactic, in which there was preoccupation with aspects of curricular content to be taught e and how to teach it; and education with an intellectual dimension, a perspective that favored the creation of undergraduate courses and Pedagogy and promoted the teachers' education to higher education, once it incorporated research and knowledge production to the teachers' education.

Keywords: Teachers' education. Teacher professionality. Teacher professional knowledge. 


\section{Introdução}

A desintelectualização docente que se observa no Brasil, agravada pela simplificação da formação de professores em contraste à crescente complexificação do ato de ensinar, tem se constituído em tendência legitimada pelas diretrizes nacionais da formação docente, as quais têm sido expostas a diversas mudanças ao longo das últimas três décadas. $\mathrm{E}$ o processo de desintelectualização do professor tem impactado negativamente nos processos educativos escolares, ao mesmo tempo em que tem contribuído para produzir um sistema educacional alienante, legitimador das assimetrias sociais e econômicas provocadas pelo capitalismo. Em face a este processo, diferentes perspectivas de formação docente têm se consolidado, as quais decorrem sobretudo de agentes externos e processos intervenientes nas políticas, programas e ações de formação de professores em nosso país.

Neste sentido, a discussão sobre as perspectivas de formação docente pressupõe que examinemos os modos de conceber e promover a formação de professores no Brasil ao longo da história. Assim, realizamos um breve resgate histórico sobre as distintas iniciativas de formação de professores em face ao qual evidenciamos os principais movimentos e políticas de formação docente desde a colonização portuguesa até os dias atuais, bem como de algumas das influências sobre a consolidação da formação docente no país. Esta análise é pertinente, pois é uma forma de entendermos os processos de mudança de foco na formação de professores ao longo da história e o agravamento dos processos de desintelectualização da formação e da profissão. Reportando-nos a autores de base sobre esta temática e apoiados nos pressupostos relativos aos conhecimentos profissionais docentes propostos por Lee Shulman, argumentamos a necessidade e relevância dos processos formativos de professores atribuírem centralidade aos conhecimentos científicos do conteúdo e curriculares na formação do professor, bem como resgatar e valorizar os conhecimentos teóricos e científicos basilares na formação e prática docente como forma de contrapor-se a tendência de desintelectualização docente e as implicações sociais decorrentes deste processo.

Mediante nossas análises foram evidenciadas quatro perspectivas de formação de professores nos distintos momentos históricos e políticos do país, em face aos quais esta questão vem assumindo importância: formação centrada na aprendizagem dos conteúdos a ensinar, formação centrada na apropriação de técnicas e recursos de ensino, formação centrada na dimensão didática e do conteúdo curricular e, também, formação com uma dimensão intelectual.

\section{Breve histórico da formação de professores no Brasil}

Discussões e estudos sobre a temática da formação de professores, especialmente sobre as perspectivas de formação predominantes em diferentes períodos históricos, ISSN 2526-2882 
permitem compreendermos as alternâncias político-econômicas pelas quais atravessou a educação no Brasil e, portanto, a consolidação da formação docente enquanto dimensão educacional estruturante. De acordo com Vieira e Gomide (2008), a questão da formação de professores no Brasil remonta a chegada dos portugueses, com o ratio studiorum jesuítico, método de ensino que prezava pela transmissão oral da fé católica. Assim, a influência da religião é marcante desde os primórdios da educação no país. Os sacerdotes eram treinados para o cumprimento de tarefas pastorais, como pregação, liturgia e práxis sacramental. Uma vez preparados para tal, eram considerados aptos a educar os homens livres, sempre com ênfase na retórica, especialmente a presente na obra de Cícero7 ${ }^{7}$ A erudição, à época, era considerada a habilidade de exercitar a rapidez de elocução, debater os assuntos com perspicácia, definir e analisar temas, rebuscar as definições com metáforas e alegorias. Para formar tais habilidades,

[...] os primeiros professores brasileiros receberiam uma formação baseada nos clássicos antigos, voltada a padrões da sociedade europeia cristã que privilegiavam a retórica com a eloquência ciceroniana como marca na formação de representantes da Companhia de Jesus. Essa formação, recebida em Portugal ou, mais tarde, no Brasil, constituía a primeira e marcante influência externa na formação de professores da terra recém conquistada. (VIEIRA e GOMIDE, 2008, p. 3837).

Estas autoras acrescentam que esse modelo de formação predominou até o final do século XVIII, quando foi introduzida a Reforma Pombalina, a qual tomou lugar em 1759 quando o governo português, sob o reinado de Dom José I e tendo na figura do Marquês de Pombal seu secretário de Estado, desmantelou a estrutura administrativa baseada na educação religiosa jesuítica e instituiu, em seu lugar, as aulas régias. O ideário pombalino tinha inspiração iluminista e propunha uma educação leiga, voltada ao progresso científico e difusão do saber. Para tal, objetivava a disseminação de uma cultura de base, abandonando a tradição da oralidade pura em direção ao desenvolvimento da leitura, escrita e cálculo (VIEIRA e GOMIDE, 2008).

As aulas régias eram ministradas por professores selecionados por meio de concursos públicos. Para candidatar-se, os interessados deveriam possuir formação básica, que consistia nos "estudos menores". Estes estudos envolviam aulas de ler, escrever e contar - também chamadas de "primeiras letras" -, e também pelas aulas de humanidades, que inicialmente abrangiam gramática latina, língua grega, língua hebraica, retórica e poética; ao longo dos anos, foram acrescidas outras cadeiras, como, por exemplo, Filosofia Moral E

7 Cícero foi um advogado, político, escritor, orador e filósofo grego da Antiguidade Clássica. Em 46 a.C. escreveu um discurso sobre a retórica chamado De Oratore, que se tornou um manual para os oradores do período e períodos posteriores. 
Racional. Porém, estas ideias não chegaram a se consolidar no Brasil devido a uma ruptura que veio acontecer a partir da Proclamação da Independência, em 1822, mediante a preocupação com a organização da instrução popular como parte do projeto de desenvolvimento da nação. A crescente demanda por escolas, à época, trouxe a necessidade de mais professores (TANURI, 2000; SAVIANI, 2009). E ao longo deste período, verificaram-se diferentes momentos na consolidação da formação de professores no Brasil.

\section{O despontar da formação de professores no Brasil (1827-1890)}

De acordo com Vieira e Gomide (2008) a formação de professores no país começa efetivamente em 15 de outubro de 1827 mediante a implantação da Lei das Escolas de Primeiras Letras, que exigia dos aspirantes ao cargo de professor se instruírem no método de ensino às próprias expensas, nas capitais de suas respectivas províncias. Essa primeira política de formação, vamos assumi-la assim aqui, apresentava caráter eminentemente prático baseado no modelo de "professores adjuntos", que consistia em promover a formação do candidato à docência inserindo-o nos locais de prática para aprender a docência com um professor experiente por meio da mera observação de seu trabalho.

Posterior a esta proposta e avançando na direção de um modelo mais formal de formação docente foi promulgado o Ato Adicional de 1834, que estimulava as províncias a adotar o modelo das Escolas Normais que, à altura, predominava na Europa. Foram criadas, então, as primeiras Escolas Normais, que apesar de serem guiadas por um ideal de formação pedagógico-didática, acabaram reproduzindo o modelo das Escolas de Primeiras Letras. Esse primeiro momento histórico da formação de professores foi o mais longo e duradouro, tendo persistido até o final do século XIX (TANURI, 2000; VIERA e GOMIDE, 2008; SAVIANI, 2009). Saviani (2009) classifica este primeiro momento, que se estende até a criação das Escolas Normais, como um período de “ensaios” na formação de professores no Brasil.

\section{A consolidação de um primeiro modelo de formação: as Escolas Normais (1890-} 1932)

O segundo momento da formação docente no país se inicia em 1890 mediante a proposição da reforma paulista para a educação nacional. Segundo os reformadores, as Escolas Normais, ao replicar o currículo das Escolas de Primeiras Letras, acabaram por fracassar na tarefa de preparar adequadamente os professores para a docência. Devido à insuficiência do programa de estudos dessas instituições, tornou-se urgente e necessário reformá-las, emergindo, portanto, um novo modelo de escola de professores. Tratou-se, assim, da primeira tentativa de configuração de um locus específico de formação docente, com aprofundamento do currículo, mas com um enfoque ainda prático. Essa ênfase prática 
da docência no período foi, sobretudo, reflexo da influência das pedagogias norte-americanas que marcaram aquela época (TANURI, 2000).

\section{A consolidação de um modelo coerente de formação: os Institutos de Educação (1932-1939)}

Um terceiro momento, curto, porém decisivo, verificou-se entre 1932 e 1939, com as reformas propostas por Anísio Teixeira, no Distrito Federal, e Fernando de Azevedo, em São Paulo, que culminaram na criação dos Institutos de Educação. Estas instituições incorporaram a seus programas de estudos a pedagogia, campo do saber emergente na época; e se propuseram a ser não apenas centros de ensino, mas também, de pesquisa. Para alcançar tais propósitos, os Institutos precisavam dispor de infraestrutura diferenciada, incluindo salas de aula para ensino e prática/pesquisa da docência, bibliotecas equipadas e atualizadas, filmotecas, museus e radiodifusão. (TANURI, 2000; VIERA e GOMIDE, 2008)

Paralelamente aos Institutos de Educação, as Escolas Normais continuaram sua consolidação nesse período, contudo, baseadas em um modelo de formação que se diferenciava pelo fato de centrarem-se nos conteúdos a ensinar (SAVIANI, 2009) e se destinarem à formação dos professores para o ensino primário.

\section{Formação docente em nível superior e a criação do curso de Pedagogia (1939- 1971)}

Dada a natureza explicitamente voltada à pesquisa científica e a consolidação da pedagogia como campo do saber, em 1939 os Institutos de Educação foram elevados a nível universitário, sendo incorporados pelas universidades: surgiram, então, os cursos de Licenciatura e de Pedagogia. Este aspecto constitui-se em um marco para a formação de professores no Brasil, pois caracterizava a transição de um modelo de formação centrado na prática para um modelo mais amplo, que enfatizava as teorias e os conteúdos culturaiscognitivos. Caracterizava também a elevação da formação de professores ao nível superior. As Escolas Normais, por sua vez, prosseguiram com o modelo de formação voltado à prática, coexistindo aos Institutos de Educação até o início dos anos 1970, quando os militares passaram a ditar os rumos para a educação no país e propuseram novas mudanças em relação à educação e à formação de professores (TANURI, 2000; VIEIRA e GOMIDE, 2008), mudanças estas que levaram a extinção das escolas normais. 


\section{Renovação da formação básica: o fïm das Escolas Normais e a criação da HEM (1971-1996)}

De acordo com Tanuri (2000), mediante a tomada do poder pelos militares as Escolas Normais foram substituídas, em 1971, pela Habilitação Específica de Magistério (HEM), promovida pela Lei de Diretrizes e Bases n. ${ }^{\circ}$ 5692, de 11 de agosto 1971 e pelo Parecer do MEC n. ${ }^{\circ}$ 349, de o6 de abril de 1972 (SAVIANI, 2009). Nesse modelo, os aspirantes à docência para os anos iniciais do ensino fundamental, denominado à época de "ensino primário", eram formados na modalidade específica em nível de 2.0 grau (atual Ensino Médio), paralelamente aos cursos superiores de Pedagogia. A formação promovida por este modelo apresentava um caráter fortemente tecnicista, devido à concepção pragmática de educação embasada na teoria do capital humano, referencial teórico predominante à época. Essa teoria, desenvolvida pela Escola de Chicago a partir dos trabalhos dos economistas norte-americanos Theodore Schultz e George Joseph Stigler, descreve o capital humano como um conjunto de habilidades, capacidades e destrezas dos indivíduos que, no sistema capitalista, se convertem em valor de troca e/ou força de trabalho (COSTA, 2009).

Entretanto, este modelo, aligeirado e tecnicista, rapidamente mostrou-se insuficiente e inadequado ao propósito de preparar para a docência, o que levou à criação, em caráter emergencial, no ano de 1982, do projeto Centros de Formação e Aperfeiçoamento do Magistério (CEFAM). Esses centros assumiram o objetivo de corrigir as lacunas e deficiências da HEM e serviram essencialmente como uma revitalização das Escolas Normais, tanto em relação aos métodos e teorias quanto de infraestrutura e, apesar dos resultados iniciais positivos, o projeto foi interrompido quando seu alcance ainda era restrito (SAVIANI, 2009).

Relativamente a este importante momento de consolidação da formação de professores no Brasil, Tanuri (2000) destaca que além da descaracterização da formação, a própria profissão foi afetada pela ausência de políticas e ações voltadas à carreira e remuneração destes profissionais, o que acabou por acentuar a desvalorização social da profissão.

\section{Oficialização da formação docente em nível superior: de 1996 até os dias atuais}

A retomada da democracia no país, após o fim da ditadura militar em 1985, trouxe novos rumos à educação, que vieram a concretizar-se com a promulgação da Lei de Diretrizes e Bases de 20 de dezembro de 1996 sob o n. ${ }^{\circ}$ 9394/96, marco recente e de grande relevância para a consolidação da formação de professores no Brasil. Esta fase, que podemos assumir como momento atual da formação dos professores no país, iniciada com a LDB de 1996, representa um movimento concreto em direção à regulamentação da formação para a ISSN 2526-2882 
docência na educação básica, elevando este processo ao nível superior, ao mesmo tempo em que se constitui em tentativa de dirimir as deficiências deixadas pelos modelos de formação anteriores. Em outras palavras, embora a discussão sobre a elevação ao nível superior da formação de professores para a docência no ensino básico tivesse perpassado todo o século XX, é somente com a aprovação da LDB de 1996 que a formação em nível superior começa a ser oficialmente referenciada. Além disso, surgiram e foram regulamentados os Institutos Superiores de Educação, as Escolas Normais Superiores e definiu-se um novo perfil para o curso superior de Pedagogia (SAVIANI, 2009).

Por fim, o percurso histórico traçado por Saviani (2009) e Tanuri (2000) evidencia que a regulamentação da formação de professores no Brasil, seguida de uma efetiva preocupação com este processo, assim como a própria profissionalização docente são muito recentes. Evidencia, ainda, uma tendência à descontinuidade dos modelos de formação instituídos, aspecto este que contribuiu para agravar as fragilidades da formação de professores em nível nacional. Portanto, a formação docente parece não ter encontrado um caminho a seguir, pois apesar de se terem experimentado diferentes modelos formativos neste percurso, não houve uma efetiva ruptura com os sistemas infrutíferos de formação que se pretendia suplantar, nem rompimento com as influências externas ao campo da educação (SAVIANI, 2009).

\section{Processos intervenientes internos e externos na formação de professores no Brasil}

Para além de compreendermos o percurso histórico da consolidação da formação docente relativamente às concepções predominantes e iniciativas implementadas, faz-se importante nesta discussão evidenciarmos as escolas e os movimentos de formação de professores externos, que influenciaram os modelos formativos no Brasil para, assim, entendermos como se deu esta influência. Conforme apontam Vieira e Gomide (2008), da mesma forma que a descontinuidade nas iniciativas de formação docente no Brasil deixou prejuízos à educação de modo geral, também a importação de modelos estrangeiros, especialmente na primeira metade do século XX, impactou negativamente na consolidação de uma proposta de formação nacional, pois estes modelos, embora bem-sucedidos nos seus países de origem, não se mostraram adequados à realidade brasileira.

Da ratio studiorum até as Escolas de Primeiras Letras, a educação e a formação de professores no Brasil são marcadas pela influência europeia, especialmente do modelo francês, de ideário iluminista, reflexo de um projeto nacional de educação emprestado às elites, de formação cultural europeia (TANURI, 2000). Quando do surgimento das Escolas Normais, no século XX, já era marcante a influência norte-americana, dados os interesses 
capitalistas que viriam a pairar sobre nosso sistema educacional, com ênfase nos pressupostos de John Dewey, de quem falaremos mais à frente. Contudo, havia, à época, uma postura bastante ingênua em relação à transformação da realidade educacional na qual o Brasil encontrava-se, pois acreditava-se que por meio destes modelos seria possível resolver eficientemente os problemas existentes. Além disso, havia um aspecto agravante: a cada reforma buscava-se trazer novas ideias, metodologias e práticas e ignorava-se a realidade do país. Em outras palavras, tentava-se ajustar a realidade brasileira aos padrões internacionais de educação com o intuito de mostrar que as reformas eram necessárias e eficientes (VIEIRA e GOMIDE, 2008).

Estas influências aos modelos experimentados no Brasil foram propostas, abandonadas e, às vezes, retomadas, na medida em que alternavam-se os ideais políticoeconômicos que dirigiam o país nos diferentes momentos históricos. Assim, pode-se sumarizar as alternâncias destacando que ao longo do domínio de Portugal, havia forte influência dos modelos europeus, implementados geralmente em face aos contextos de reformas econômicas que almejavam colocar o Brasil em processo de desenvolvimento (VIERA e GOMIDE, 2008).

Após a Proclamação da República, a busca pela consolidação da educação mediante a proposição de um projeto nacional de instrução popular avançou no século XX, e com o país em franca industrialização, a influência dos ideais capitalistas e organismos econômicos tornou-se evidente. Esta tendência emergiu no bojo do movimento de expansão industrial mundial devido à necessidade de qualificação da força de trabalho para o modelo fordistataylorista, que se instaurava na sociedade brasileira à época. Consoante a este ideal, na segunda metade do século XX a influência do Banco Mundial sobre a educação mundial e, consequentemente, sobre a formação de professores, concretizou-se com a edição e publicação de documentos norteadores para uma educação voltada ao desenvolvimento econômico das nações (FREITAS, 2002). Assim, a educação que no século XIX seguia os ideais de democracia, liberdade e desenvolvimento humano, de orientação positivista, voltase, no século XX, para a legitimação do sistema capitalista, interferindo diretamente nos currículos de formação de professores, pois tornava-se necessário redefinir e controlar os processos formativos para formar professores com perfil adequado para levar a frente o plano de desenvolvimento econômico vigente (VIEIRA e GOMIDE, 2008).

E assim a questão da formação de professores no Brasil percorreu pouco mais de 100 anos, atravessando duas transições de século, período este em que transcorreram grandes alternâncias político-econômicas paralelamente a um contínuo movimento de mudanças sociais e culturais. E inevitavelmente que esse cenário de mudanças interferiu fortemente nos rumos da educação no país, de modo que diferentes modelos formativos 
foram experimentados como forma de adequar os percursos formativos dos professores aos ideais político-econômicos vigentes nestes distintos momentos históricos.

\section{Conhecimentos profissionais na formação de professores}

Lee Shulman (1985) apresenta um primeiro modelo teórico relativo aos tipos de conhecimento necessários à formação e prática docente. Ele destaca, em um primeiro momento de seu estudo, uma perspectiva de conhecimentos profissionais assentada na tríade de conhecimentos: content knowledge - relativo aos conhecimentos científicos acerca do conteúdo curricular a ser ensinado; pedagogical content knowledge - inerente aos conhecimentos pedagógicos do conteúdo, ou seja, os métodos e estratégias para se ensinar determinado conteúdo; e curricular knowledge - relacionado ao conhecimento sobre o currículo, enquanto percurso de aprendizagem e desenvolvimento.

As contribuições do trabalho de Shulman deram novos rumos para os processos de formação de professores ao redor do mundo. Além de reconhecer a diversidade dos conhecimentos basilares na formação e prática docente, este autor traz a concepção de conhecimento pedagógico do conteúdo como integrador entre conteúdo curricular e conteúdo científico, dimensões estas da formação que historicamente eram colocados em extremidades diametralmente opostas nas propostas de formação implementadas nos distintos momentos. Para ele, conteúdos não deveriam eclipsar didática, ou vice-versa. Teoria e prática deveriam estar sempre em equilíbrio, dentro de um percurso formativo coeso.

Mais tarde, Shulman (2014) aprofundou sua categorização mediante o desdobramento de alguns conhecimentos centrais em sete categorias de conhecimentos profissionais: conhecimento do conteúdo; conhecimento pedagógico geral - referente aos princípios e estratégias de gerenciamento e organização de sala de aula, que transcendem o conhecimento científico; conhecimento do currículo; conhecimento pedagógico do conteúdo - intersecção entre conteúdo científico e pedagogia que ele define como o conhecimento específico dos professores; conhecimento dos alunos e de suas características; conhecimento de contextos educacionais - funcionamento do grupo ou da sala de aula, gestão e financiamento dos sistemas educacionais, características das comunidades e suas culturas; e conhecimento das finalidades, propósitos e valores da educação, suas bases históricas e filosóficas. Este repertório de conhecimentos profissionais evidencia a complexidade da profissionalidade docente, o que remete à necessidade de uma formação adequada, capaz de abranger e equilibrar estes diferentes conhecimentos em seu programa de estudos.

No contexto desta categorização ampliada, o conhecimento pedagógico do conteúdo assume lugar especial, pois é este conhecimento que distingue a profissionalidade docente e equilibra conteúdo e pedagogia, destacando a importância de ambos e a complementaridade 
entre conhecimentos específicos e métodos de ensino (SHULMAN, 2014). Portanto, conforme destacado por Shulman (2014) e corroborado por Roldão (2014), o conhecimento pedagógico não se sobrepõe ao conhecimento do conteúdo e vice-versa, mas é no delicado equilíbrio destas duas categorias de conhecimentos profissionais que a especificidade da profissionalidade docente se concretiza.

Argumentando em favor de uma formação docente consistente e qualificada, Giroux (1997) defende que o professor, pela complexidade da função que realiza, precisa assumir o papel de intelectual transformador e, portanto, a formação voltada à dimensão intelectual é elemento da constituição da profissionalidade. Adentrando na discussão sobre a construção da profissionalidade docente e nas questões ocultas que permeiam os currículos de formação de professores, defende uma concepção de "professores como intelectuais transformadores" e sugere a adoção de uma nova postura profissional por parte dos docentes, dada sua função social e seu local de trabalho, ambos inextricavelmente atrelados às questões de poder e controle (GIROUX, 1997). Segundo o autor, elevar o professor ao status de intelectual é conditio sine qua non para a construção de uma sociedade melhor, pois o professor enquanto intelectual transformador não age como reprodutor das injustiças e mazelas do sistema no qual está inserido, mas sim, torna-se sujeito ativo na construção de um mundo mais justo e democrático, educando cidadãos críticos.

Para um professor tornar-se um intelectual transformador, segundo Giroux (1997), é essencial que sua formação não seja instrumental ou tecnicista, esvaziada de "capital cultural”. Pelo contrário: deve ser crítica, reflexiva e diversificada, sempre pautada nas questões científicas, históricas, sociais, culturais, políticas e econômicas. Não obstante, a intelectualização do professor lhe permite também refletir criticamente sobre sua própria formação, contestando-a quando necessário e reivindicando maior participação nas decisões que a envolvem.

E, portanto, as perspectivas apresentadas por Shulman e Giroux, por sua abrangência, profundidade e coerência, têm embasado análises sobre processos e modelos de formação de professores em diferentes contextos e realidades, evidenciando propostas de formação mais consistentes na direção da concretização de processos educativos escolares qualificados e com possibilidade de transformação social.

\section{Os modelos formativos evidenciados ao longo da história da educação no Brasil}

$\mathrm{O}$ percurso histórico da educação no Brasil, sobretudo no que diz respeito às iniciativas de constituição de um modelo formativo e de regulamentação da formação de professores em nível nacional, foi marcado por perspectivas diversas, cujos delineamentos incidiam sobre focos muito distintos deste processo. E evidentemente estas perspectivas 
acabaram por determinar os rumos dos processos educativos escolares, uma vez que os focos de cada uma dirigiam-se a um modelo político-econômico distinto. Mediante os resultados de estudos conduzidos pelos autores de base neste texto, a saber Saviani (2009), Vieira e Gomide (2008) e Tanuri (2000), destacamos aqui quatro modelos principais: formação voltada ao conteúdo a ensinar, formação centrada em métodos e técnicas de ensino, formação centrada nos conteúdos curriculares e didática e, também, formação com uma dimensão intelectual.

\section{Formação voltada ao conteúdo a ensinar}

De acordo com Tanuri (2000), o foco dos primeiros momentos de formação, de professores adjuntos, no qual se assistia e se imitava um modo de lecionar, era extremamente conteudista, voltado unicamente para a transmissão dos conteúdos a ensinar em sala de aula por meio de um único método: o da observação da prática de um professor experiente.

Este modelo, marcante por um logo período no Brasil desde a instituição do ensino jesuíta, embora se mostrasse bastante limitado e inadequado para promover a formação de professores, constituiu-se na concretização de uma primeira iniciativa de formação de professores uma vez que havia, à altura, significativa demanda por profissionais da educação em um momento em que não se dispunha de instituições e programas formais destinados a este fim. Portanto, este modelo, baseado na observação do ato de ensinar em sala de aula, por um lado acabou por reproduzir modos de ensinar praticados pelos professores em exercício, com seus pontos positivos e limitações e, por outro, pode ter contribuído para as primeiras reflexões sobre as dimensões da formação e prática docente, uma vez que neste modelo nem sempre havia a aprendizagem sobre o conteúdo a ensinar, mas sim, sobre como transmiti-lo e que por vezes replicava as problemáticas do ensino à época.

\section{Formação centrada nos métodos e técnicas de ensino}

A mudança de foco na formação de professores, em que a ênfase nos conteúdos a ensinar deu lugar à preocupação com os métodos de ensino concretizou-se mediante a criação da Escola Normal, que emergiu com força na década de 1930 seguindo uma tendência mundial. Nesse momento histórico, a questão dos métodos desloca o foco da atenção e esforços do ensino para a aprendizagem, aspecto este que contribuiu à constituição de uma cultura escolar mais simplificada e interferiu na organização dos modelos de formação de professores implementados naquele momento. À luz das pesquisas sobre os campos do saber emergentes, como biologia e psicologia, surgiram teorias empíricas, tais como a do "método de ensino intuitivo", de John Dewey, que focava na aplicabilidade do conhecimento e uso de materiais, processos que acabaram secundarizando o papel do docente (VALDEMARIN, 
2004). Essa ênfase excessiva nos métodos de ensino e na aprendizagem acarretou um empobrecimento do currículo de formação de professores quanto aos conhecimentos científicos.

Este modelo sofreu uma retração ao final dos anos 1930, em detrimento de um modelo mais amplo, que originou-se no contexto dos Institutos de Educação. Contudo, ainda no final do século XX, verificou-se uma rápida descontinuidade dos modelos da época, evidenciada nas sucessivas mudanças de foco da formação: nos anos 60 e 70, com o surgimento da HEM, a formação era tecnicista, nos anos 80 ocorre um rebate ao tecnicismo com a reforma dos CEFAM e no início dos anos 90, retorna-se ao modelo tecnicista (FREITAS, 2002). Ressaltamos que embora este modelo havia se consolidado neste período, no contexto das Escolas Normais o modelo centrado nos conteúdos a ensinar acabou predominando até o final da década de 1930, de modo que as influências acima referidas manifestaram-se efetivamente nos Institutos de Educação.

Esta inconstância é chamada por Roldão (2007) de "movimentos pendulares" e por Saviani (2012) de "curvatura da vara": as duas denominações convergem ao explicitar a oscilação extrema que os programas de formação docente sofrem historicamente no país e no mundo. A cada nova reforma, procuravam os reformadores e legisladores ir em direção diametralmente oposta às políticas vigentes até aquele momento. Essas rupturas, geralmente centradas nos modelos, mas não nas bases das propostas de formação, foram extremamente prejudiciais pois, em várias momentos, programas e políticas eram descontinuados antes que estudos mais detalhados e conclusivos pudessem aferir seu grau de eficiência.

\section{Formação centrada nos conteúdos pedagógicos e curriculares}

Ainda na primeira metade do século XX no Brasil, a educação sofreu transformações devido às mudanças no cenário político e econômico que levaram a uma discussão sobre o papel da escola na construção da sociedade. Em termos de formação de professores, este momento é marcado pela criação dos Institutos de Educação. A esta altura começou-se a pensar a formação de professores em nível superior e deu-se mais atenção para a questão da pesquisa e da produção do conhecimento, como evidenciado nas diretrizes que guiavam os Institutos de Educação.

Porém, essas primeiras tentativas de superiorização da formação docente foram atravessadas por questões políticas escusas e por forte interferência da Igreja Católica, resultando em embates entre Fernando de Azevedo, criador e defensor da ideia dos Institutos de Educação, e as Pontifícias Universidades Católicas no final dos anos 1930 (EVANGELISTA, 2003). Ao final da primeira metade do século XX, as escolas e as instituições formadoras de docentes tornaram-se palco de uma disputa de poder entre ISSN 2526-2882

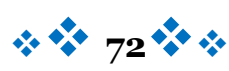


entidades econômicas, políticas e religiosas, cada qual com seu projeto de educação com vistas à manutenção do poder que exerciam sobre a sociedade naquele período.

Relativamente a este modelo, destacamos que especialmente na segunda metade do século XX fortaleceram-se as pedagogias do "aprender a aprender", que de acordo com Duarte (2010) influenciaram fortemente a formação e a prática docente. Centradas na negação do ensino tradicional e inspiradas pelas ideias de John Dewey, essas pedagogias priorizavam os conhecimentos tácitos em detrimento dos conhecimentos científicos. Além disso, atribuíam maior importância aos métodos pelos quais os alunos adquiriam o conhecimento do que ao próprio conhecimento. Nesta perspectiva, a formação de professores acabou por retomar o foco a aprendizagem de "técnicas" de ensino, produção de materiais didáticos, entre outras atividades pragmáticas. Nessa linha de trabalho, o professor tornou-se mero organizador e reprodutor de atividades, conforme assinala Duarte (2010, p. 38):

Se o conhecimento mais valorizado na escola passa a ser o conhecimento tácito, cotidiano, pessoal, então o trabalho do professor deixa de ser o de transmitir os conhecimentos mais desenvolvidos e ricos que a humanidade venha construindo ao longo de sua história. O professor deixa de ser um mediador entre o aluno e o patrimônio intelectual mais elevado da humanidade, para ser um organizador de atividades que promovam o que alguns chamam de negociação de significados construídos no cotidiano dos alunos. Mesmo quando os projetos surgidos nas atividades escolares demandem algum tipo de conhecimento proveniente do campo da ciência, o que articula os conhecimentos é o objetivo de formação de habilidades e competências requeridas pela prática cotidiana.

Portanto, verifica-se que o modelo centrado nos conteúdos curriculares e didáticos, subjacente sobretudo na formação promovida nos Institutos de Educação, foi sendo gradativamente abandonado, dando lugar a um modelo centrado nas técnicas de ensino. Consideramos, entretanto, que desvalorizar o conhecimento científico específico da ação docente é desvalorizar a própria profissão e os ideais e propósitos de educação. A formação docente acaba "esvaziada”, por que também são os currículos e os objetivos aos quais se destinam. Esse esvaziamento da formação e da prática docente acaba transformando o professor em ator de um processo de alienação na transmissão do conhecimento escolar.

\section{Formação com uma dimensão intelectual}

Um modelo inovador e, certamente, muito interessante e adequado à formação de professores, surgiu no contexto da reforma proposta por Fernando de Azevedo e Anísio Teixeira, colocada em prática nos Institutos de Educação. Esta proposta ressaltou a dimensão intelectual do processo formativo, oportunizando aos professores tornarem-se pesquisadores e desenvolvedores de conhecimentos sobre a docência e sobre sua própria formação. Este 
ideal foi viabilizado mediante a incorporação de escolas-modelo aos Institutos de Educação, o que permitia o desenvolvimento de propostas pedagógicas inovadoras em sala de aula e, sobretudo, a realização de pesquisas. Esta perspectiva de formação deu origem aos cursos de licenciatura e pedagogia e elevaram a formação de professores ao nível universitário. Esta perspectiva anunciou um novo modelo de formação de professores no Brasil, que deu-se mediante transição de um modelo centrado na prática para um modelo mais amplo, que enfatizava as teorias e os conteúdos culturais-cognitivos.

Esta perspectiva é destacada por Giroux (1997) ao enfatizar que a formação do professor deve oferecer bases que o estimulem a assumir o papel de pesquisador e produtor de conhecimentos e não mero reprodutor de técnicas ou consumidor de teorias. Um professor com formação mais ampla e profunda, e ao mesmo tempo crítico e reflexivo, tem possibilidade e condições de reorganizar o trabalho escolar e a prática profissional, manifestando autonomia nas escolhas referentes a currículo, materiais didáticos, organização estrutural das instituições de ensino entre outros itens, contribuindo assim para a superação de questões como a alienação e a manutenção das relações assimétricas de poder, que a escolarização insiste em perpetuar.

Da mesma forma Roldão (2007) e Duarte (2010) ressaltam a dimensão intelectual da profissionalidade docente, no sentido de que o professor deve ser mediador entre a criança e o patrimônio cultural da humanidade. Esta é uma tarefa complexa, que não é dom, técnica ou vocação: é profissionalidade de ensinar, que deve ser legitimada por um corpus de conhecimentos específicos, exigentes e complexos; que equilibre, assim como sugere Shulman (1985; 2014), variadas componentes científicas e pedagógicas.

\section{Discussão e considerações fỉnais}

Relativamente à consolidação de um modelo coerente e consistente de formação de professores no Brasil, a história nos mostra que este propósito ainda não foi plenamente alcançado, embora já tenhamos experimentado propostas com este viés. E a literatura na área tem corroborado este aspecto na medida em que aponta graves deficiências e ressalta a baixa qualidade e eficiência dos processos frequentemente implementados, sobretudo a partir de meados do século passado, contrapondo as perspectivas sugeridas por Lee Shulman e Henry Giroux.

Além disso, embora ao longo da história alguns avanços tenham sido alcançados, a formação docente ainda está sujeita às demandas econômicas da sociedade capitalista, em que a primazia pelo lucro supera qualquer noção que esteja relacionada a uma educação de qualidade, democrática e libertadora. A medida em que a educação no Brasil tem sido influenciada pelas ações de grupos hegemônicos, que a utilizam como meio de consolidar sua 
supremacia e impor seu projeto político (TANURI, 2000), a formação de professores tem sido fortemente influenciada, devido ao tipo de profissional que se deseja para legitimar tais interesses de dominação por meio do ensino, os processos formativos têm refletido estes direcionamentos.

Entre avanços e retrocessos, a dimensão histórica da formação de professores é complexa e evidencia uma verdade incômoda: a educação no Brasil e, consequentemente, o projeto de formação dos educadores, sempre estiveram atrelados a movimentos políticoeconômicos históricos, servindo aos interesses de dominação de grupos hegemônicos de dentro e de fora do Brasil (TANURI, 200o), convergindo, portanto, para modelos formativos simplificados e esvaziados em termos dos conteúdos intelectuais cognitivos. E nossa análise mostra essa tendência, uma vez que ao longo da história predominaram os modelos centrados no conteúdo a ensinar e na aprendizagem de métodos e técnicas de ensino.

Estas influências, reunidas em modelos educacionais deslocados em relação às reais demandas nacionais, gerou fortes dicotomias na questão da formação de professores, que se expressam historicamente nas tensões entre conteúdos e métodos de ensino e entre formação teórica e prática (VIEIRA e GOMIDE, 2008; SAVIANI, 2009). Entre a emulação de modelos estrangeiros e oscilação de focos de formação de professores, a temática no Brasil viveu uma constante crise identitária, crise que, parece-nos, ainda buscam-se estratégias para superar. Essa tarefa de superação parece-nos árdua, uma vez que os legisladores e reformadores parecem não compreender que "[...] nenhuma formação pode ser analisada senão na complexa trama social da qual faz parte” (MARTINS, 2010, p. 14).

Por outro lado, pelo já exposto, credita-se à formação do professor o potencial de interferir na qualidade dos processos de ensino e aprendizagem na escola e, também, na constituição da profissionalidade docente, pois os processos formativos podem influenciar diretamente as estruturas sociais baseadas na divisão social do trabalho e na estratificação social. Entretanto, como aponta Mészáros (2010), pequenos ajustes nas políticas e modelos educacionais são infrutíferos para solucionar os problemas da educação. Portanto, na perspectiva deste entendimento, as mudanças educacionais decorrentes das alternâncias político-econômicas pelas quais o Brasil atravessou, buscavam transformar a educação e a estrutura social vigente em cada momento, mas falharam por apoiarem-se em ações pontuais e em propósitos de natureza econômica. Para além disso, as influências contribuíram para o empobrecimento dos processos de formação de professores na medida em que as diretrizes dos cursos de licenciatura passaram a atender aos interesses econômicos, e a dimensão intelectual da formação do professor foi sendo suplantada pela dimensão prática. E este aspecto tem contribuído para a desintelectualização da formação e prática docente. 
Nesta direção, uma perspectiva de formação de professores que se apresenta como possibilidade de transcender aos modelos reducionistas, constituindo um modelo abrangente e sólido de formação, e capaz de impactar a ordem social, é proposta por Giroux (1997), o qual encontra embasamento teórico em Shulman (2014). Esta perspectiva é corroborada por Duarte (2010) e Saviani (2009) ao afirmarem que a formação do professor ocupa lugar de destaque na construção de uma nova educação, pois é preciso formar professores capazes de promover a emancipação, numa perspectiva crítico-dialética de educação como fenômeno histórico que auxilie no combate às assimetrias produzidas pela divisão social do trabalho, da posse dos meios de produção e da estratificação social. Em síntese, é urgente e necessário superar as concepções pragmáticas de educação, que relegam o corpus de conhecimento produzido pela humanidade a um segundo plano.

Mediante estas compreensões ressaltamos a relevância de se valorizar e promover a formação intelectual de professores, na perspectiva de Giroux (1997). Para tanto, faz-se necessário promover importantes mudanças nos processos formativos, a começar pela formulação de novos programas, novos currículos de formação docente. Nesse sentido, Zabalza (2004) preconiza que a universidade é cenário específico e especializado da formação, sendo que tal formação não se dá apenas na aquisição de novos conhecimentos, mas também no desenvolvimento de novas habilidades, atitudes e valores por meio de experiências ricas oferecidas ao professor em formação. Assim, o autor elege o ambiente universitário como locus privilegiado de formação e pensa o processo formativo como desenvolvimento pessoal, e não apenas profissional, do indivíduo. Ressalta assim, o ideal da formação profissional docente ocorrer, necessariamente, em instituições de nível superior, que estimulem o futuro professor a produzir saberes provenientes de pesquisas, e não apenas acumular conhecimentos e reproduzir técnicas.

Essa concepção de superiorização da formação docente é uma das formas pelas quais podemos tentar combater a desintelectualização docente. Para Shiroma (2009), qualquer tentativa de desvincular a formação inicial docente do ensino superior representa, além da redução de custos, intenções claras de despolitizar o processo de formação, produzindo cursos que modelam professores tecnicamente competentes, mas inofensivos politicamente. Sendo a universidade local da produção e discussão de conhecimentos, idealmente toda e qualquer formação, inicial ou continuada, deve ter o envolvimento dessa instituição para garantir que o processo não seja vazio de significado e reflexão.

Dada a importância do conhecimento científico na formação das pessoas, Saviani e Duarte (2010) defendem uma formação assentada em clássicos, cujos conceitos, teorias e obras clássicas são indispensáveis à formação humana. Para estes autores, "clássico" é entendido como o conjunto de saberes sistematizados, produzidos historicamente e que, ISSN 2526-2882 
depurados de sua fase polêmica, resistiram ao tempo e, por isso mesmo, se tornaram essenciais. Estes conhecimentos essenciais na perspectiva de Shulman (1986; 2014) abrangem a primeira categoria relativa ao "conhecimento do conteúdo", assim como a categoria derivada do desdobramento da tríade, que ele denominou "conhecimento científico do conteúdo”. E uma formação assentada nestas bases teóricas oportuniza a formação de professores como intelectuais transformadores, na perspectiva de Giroux (1997), que possam efetivamente promover uma educação voltada à transformação social.

Embora ressaltada a essencialidade dos conhecimentos do conteúdo, é importante dizer que não os consideramos mais importantes do que outros, novamente evocando Shulman (2014) e Roldão (2014) no sentido de que todas as componentes da prática docente são importantes e devem estar em equilíbrio. Se aqui destacamos o conhecimento científico, é devido à secundarização e eclipsamento que o mesmo vem sofrendo nos programas curriculares dos cursos de formação de professores. Ou seja, faz-se necessário dar centralidade esta categoria de conhecimento para que se possa promover uma formação docente sólida e que intelectualize nossos futuros educadores. Portanto, a formação de professores precisa ser equilibrada e diversificada, de modo a contemplar as diferentes dimensões de conhecimentos profissionais necessários à prática docente.

Por fim, é indispensável elevar o capital cultural dos docentes e incentivá-los à investigação e produção de conhecimento. Dessa forma, será possível não produzir, mas desenvolver profissionais que estarão muito acima da competência técnica: cidadãos críticos formadores de outros cidadãos críticos, que terão em suas mãos as estratégias, métodos e possibilidades para despertar o potencial da emancipação e, por que não, da revolução.

Revolução que não signifique apenas reformas, ajustes e acréscimos, mas que represente evolução: um rompimento com tradições ineficazes e que servem a interesses escusos. Revolução que parece cada vez mais necessária frente à invasão inexorável das alienantes demandas capitalistas da sociedade contemporânea para dentro do terreno da educação.

\section{Referências}

COSTA, Sylvio de Sousa Gadelha. Governamentalidade neoliberal, Teoria do Capital Humano e Empreendedorismo. Educação \& Realidade. Porto Alegre, v. 34, n. 2, maio/ago. 2009, p. 171-186. Disponível em: <http://www.redalyc.org/html/3172/317227054011/>. Acesso em: 15 jun. 2018.

DUARTE, Newton. O debate contemporâneo das teorias pedagógicas. In: DUARTE, Newton; MARTINS, Lígia Márcia (Orgs.). Formação de professores: limites 
contemporâneos e alternativas necessárias. São Paulo: Cultura Acadêmica, 2010, p. 33-50.

EVANGELISTA, Olinda. A formação universitária do professor: o debate dos anos 1920 e a experiência paulista dos anos 1930. In: MORAES, Maria Célia Marcondes de (Org.). Iluminismo às avessas: produção de conhecimento e políticas de formação docente. Rio de Janeiro: DP\&A, 2003, p. 21-43.

FREITAS, Helena Costa Lopes de. Formação de professores no Brasil: 10 anos de embate entre projetos de formação. Educação \& Sociedade. Campinas, v. 23, n. 80, set. 2002, p. 136-167. Disponível em: <http://www.scielo.br/pdf/es/v23n8o/12928.pdf>. Acesso em: 11 nov. 2017.

GIROUX, Henry. Os professores como intelectuais. Porto Alegre: Artmed, 1997.

MARTINS, Lígia Márcia. O legado do século XX para a formação de professores. In: DUARTE, Newton; MARTINS, Lígia Márcia (Orgs.). Formação de professores: limites contemporâneos e alternativas necessárias. São Paulo: Cultura Acadêmica, 2010, p. 13-31. Disponível em: <http://static.scielo.org/scielobooks/ysnm8/pdf/martins-9788579831034.pdf>. Acesso em: 11 out. 2017.

MÉSZÁROS, István. A educação para além do capital. 2. ed. São Paulo: Boitempo, 2010. ROLDÃO, Maria do Céu. Currículo, didáticas e formação de professores - a triangulação esquecida. In: OLIVEIRA, Maria Rita (Org.). Professor: formação, saberes e problemas. Porto: Porto Editora, 2014, p. 91-104.

. Formação docente: natureza e construção o conhecimento profissional. Revista Brasileira de Educação. Rio de Janeiro, v. 12, n. 34, jan./abr. 2007, p. 94-103. Disponível em: <http://www.scielo.br/pdf/rbedu/v12n34/ao8v1234>. Acesso em: 11 nov. 2017.

SAVIANI, Dermeval. Escola e Democracia. 42 ed. rev. Campinas: Autores Associados, 2012.

- Formação de professores: aspectos históricos e teóricos do problema no contexto brasileiro. Revista Brasileira de Educação. Rio de Janeiro, v. 14, n. 40, jan./abr. 2009, p. 143-155. Disponível em: <http://www.scielo.br/pdf/rbedu/v14n4o/v14n40a12.pdf>. Acesso em: 15 maio 2018.

; DUARTE, Newton. A formação humana na perspectiva histórico-ontológica. Revista Brasileira de Educação. Rio de Janeiro, v. 15, n. 45, set./dez. 2010, p. 422-433. Disponível em: <http://www.scielo.br/pdf/rbedu/v15n45/o2>. Acesso em: 22 maio 2018. 
SHIROMA, Eneida Oto. O eufemismo da profissionalização. In: MORAES, Maria Célia Marcondes de (Org.). Iluminismo às avessas: produção de conhecimento e políticas de formação docente. Rio de Janeiro: DP\&A, 2003, p. 61-79.

SHULMAN, Lee S. Conhecimento e ensino: fundamentos para a nova reforma. Cadernos Cenpec. São Paulo, v. 4, n. 2, dez. 2014, p. 196-229. Disponível em: <http://cadernos.cenpec.org.br/cadernos/index.php/cadernos/article/view/293/29 >. Acesso em: 02 mar. 2018.

. Those Who Understand: Knowledge Growth in Teaching. Educational Researcher. Washington, v. 15, n. 2, fev. 1986, p. 4-14. Disponível em: <http://www.fisica.uniud.it/URDF/masterDidSciUD/materiali/pdf/Shulman_1986 .pdf>. Acesso em: 14 out. 2017.

TANURI, Leonor Maria. História da formação de professores. Revista Brasileira de Educação. Rio de Janeiro, n. 14, maio/ago. 2000, p. 61-88. Disponível em: <http://www.redalyc.org/articulo.oa?id=27501405>. Acesso em: 15 maio 2018.

VALDEMARIN, Vera Teresa. Os sentidos e a experiência: professores, alunos e métodos de ensino. In: SAVIANI, Dermeval et al. (Orgs.). O Legado Educacional do Século XX no Brasil. Campinas: Autores Associados, 2004, p. 163- 203.

VIEIRA, Alboni Marisa Dudeque Pianovski; GOMIDE, Angela Galizzi Vieira. História da formação de professores no Brasil: o primado das influências externas. CONGRESSO NACIONAL DE EDUCAÇÃO - EDUCERE, 8, p. 3835-3848. Anais... Curitiba, 2008. Disponível em: <http://www.pucpr.br/eventos/educere/educere2008/anais/pdf/93_159.pdf>. Acesso em: 12 nov. 2017.

ZABALZA, Miguel Angel. O ensino universitário: seu cenário e seus protagonistas. Porto Alegre: Artmed, 2004.

\section{Biografia Resumida}

William Xavier de Almeida - Bacharel em Sistemas de Informação pela Universidade do Oeste de Santa Catarina (UNOESC). Mestrando em Educação pela Universidade Federal da Fronteira Sul (UFFS). Técnico Universitário de Desenvolvimento na Universidade do Estado de Santa Catarina (UDESC). Integrante do grupo de pesquisa GEPEM@T.

Link do Lattes: http://lattes.cnpq.br/o800599331043159 
e-mail: wxalmeida89@gmail.com

Adriana Richit - Licenciada em Matemática e Física pela URI; Mestre e Doutora em Educação Matemática pela Universidade Estadual Paulista - UNESP; pós-doutora em Educação Matemática pela Universidade de Lisboa. Professora Associada da Universidade Federal da Fronteira Sul (UFFS) e docente do programa de Pós-Graduação em Educação da UFFS; Líder do grupo de pesquisa GEPEM@T.

Link do Lattes: http://lattes.cnpq.br/2107707592550055

e-mail: adrianarichit@gmail.com 